\author{
Marian Fathy, Mohammed H El Agooz, \\ Alahmady H Samman and Engy M \\ Mostafa \\ Affiliation of authors: Ophthalmology Department, \\ Sohag University, Sohag, Egypt \\ Dates: Received: 26 December, 2015; Accepted: \\ 04 January, 2016; Published: 09 January, 2016 \\ *Corresponding author: Engy Mohamed Mostafa, \\ $\mathrm{MD}, \mathrm{PhD}$, Ophthalmology Department, Sohag \\ University, Nasr City, Sohag, 82524, Egypt, \\ +2/01005643587; E-mail: engymostafa@yahoo.com \\ www.peertechz.com \\ ISSN: 2455-1414
}

\author{
Research Article
}

\section{Anterior Segment Characteristics of Keratoconus Eyes Using Scheimpflug- Placido Topography}

\section{Introduction}

The increasing volume of patients interested in refractive surgery and the new treatment options available for keratoconus have generated a higher interest in achieving a better characterization of this pathology [1]. Keratoconus is a bilateral non-inflammatory progressive disorder characterized by corneal ectasia and thinning [2-4]. Detecting moderate and advanced keratoconus is not difficult using corneal topography and biomicroscopic, retinoscopic, and pachymetric findings [3]. Several indices have been proposed to help in the diagnosis of keratoconus and subclinical keratoconus with different topography systems [5-13]. They include quantitative descriptors such as the KISA\% index proposed by Rabinowitz and Rasheed [8], the Keratoconus Prediction Index and Keratoconus Index proposed by Maeda et al. [14]. Smolek and Klyce [7], developed a neural network classification based on corneal topography indices. Other detection schemes based on Zernike decomposition of the anterior corneal surface have been described by Schwiegerling et al. [15], and Langenbucher et al. [16]. With the Scheimpflug imaging system, corneal elevation either anterior or posterior started to be more investigated and researches debated which of the corneal surfaces had higher sensitivity in detecting keratoconus [11,1720]. Incorporating corneal thickness, corneal volume and corneal curvature using a Scheimpflug camera have been evaluated in several other articles [21,22].
The Sirius system is a relatively new Scheimpflug-placido topographer that enables rapid acquisition and processing of the cornea and anterior chamber [23].

Our study was conducted to define changes in the anterior segment of keratoconus eyes at different stages of the disease in a sample of the southern Egyptian population with special emphasis on detecting parameters that can enable objective identification of early keratoconus.

\section{Patients and Methods}

This study is a retrospective study of 500 patients (500 eyes) who were seeking refractive surgery in Sohag refractive center and diagnosed as clinical keratoconus between August 2014 and August 2015. In addition, fifty normal volunteer subjects (50 eyes) have been included as a control group. This study adhered to the tenets of the Declaration of Helsinki and was approved by the Ethics Committee, Sohag University Hospital, Egypt.

For analysis, keratoconus eyes have been classified into 4 subgroups according to Amsler-Krumeich classification [24]. The term keratoconus suspect was coined for corneal topography with abnormal localized steepening or an asymmetric bow-tie pattern, a normal-appearing cornea on slitlamp biomicroscopy, and at least 1 of the following signs: steep keratometric curvature (>47.00 D), oblique cylinder greater than $1.50 \mathrm{D}$, central corneal thickness less than 500 $\mathrm{mm}$, or clinical keratoconus in the fellow eye $[12,13,17,25,26]$. 
Eyes were considered normal if they had no ocular pathology, no previous ocular surgery, no significant refractive error, and no irregular corneal pattern. In this group, only 1 eye of each patient was evaluated (random sampling).

Exclusion criteria were previous ocular surgery, corneal scarring, trauma, pregnancy or lactation, glaucoma and causes of ocular astigmatism other than corneal i.e. lenticular astigmatism such as early cataract, lens subluxation or lenticonus.

\section{Procedure}

All patients have been subjected to comprehensive eye examination and images were acquired by Scheimpflug placido topography (Sirius, Firenze, Italy) on all eyes with software version used 1.0.5.72 (Phoenix, Costruzione Strumenti Oftalmici). The scanning process acquires a series of 25 Scheimpflug images (meridians) and 1 Placido top view image. The ring edges are detected on the Placido image so that height, slope, and curvature data are calculated using the arcstep method with conic curves. From the Scheimpflug images, the profiles of anterior cornea, posterior cornea, anterior lens, and iris are derived. Anterior surface data from both Placido images and Scheimpflug images are merged using a proprietary method. All the other measurements for internal structures (posterior corneal curvature, anterior lens surface, and iris) are derived solely from Scheimpflug data. Previous studies have reported that the system's pachymetric and shape measurements (curvature, eccentricity, elevation) have good repeatability [23,27]. Measurements were performed by a single experienced examiner (EM). Patient's eye was aligned along the visual axis using a central fixation light. Patients were instructed to blink between shots to keep eyes moist. The examination which met excellent quality of the topographic and tomographic image, alignment and anterior and posterior coverage was saved. Eyes with scans not attainable, artificial tears were added to allow better acquisition.

In this study, the following parameters were evaluated: corneal thickness (CT) at the corneal apex, the thinnest corneal thickness (TCT), anterior chamber depth (ACD) defined as the distance from the corneal endothelium to the anterior surface of the lens capsule, corneal volume in a diameter of $9 \mathrm{~mm}$, corneal volume (CV), keratometry $(\mathrm{K})$ (both anterior and posterior as well as steep and flat keratometry), corneal asphericity $(\mathrm{Q})$, corneal elevation (both anterior and posterior) with aspherotoric surface as a reference, total root mean square (RMS), RMS Coma, RMS spherical aberration (SA), RMS Astigmatism, Baiocchi Calossi Versaci front index $\left(\mathrm{BCV}_{\mathrm{f}}\right)$ and $\mathrm{BCV}$ back index $\left(\mathrm{BCV}_{\mathrm{b}}\right)$.

Schwiegerling et al. [5] and $\mathrm{Li}$ et al. [34], have shown that the following coefficients are the most relevant for keratoconus detection: vertical trefoil $c 3^{-3}$, vertical coma $3^{-1}$, horizontal coma $3^{+1}$, primary spherical aberration $\mathrm{c} 4^{0}$, and second order vertical coma $\mathrm{c5}^{-1}$. The $\mathrm{BCV}_{\mathrm{f}}$, which is expressed in micrometers, was obtained by properly combining these coefficients (from the anterior corneal surface) and weighting them by a function of the coma axis. Likewise, a linear combination of $\mathrm{c3}^{-3}, \mathrm{c3}^{-1}, \mathrm{c3}^{+1}, \mathrm{c4}^{\mathrm{o}}$, and $\mathrm{c5}^{-1}$ and information about the coma axis on the posterior Zernike decomposition were used to define the $\mathrm{BCV}_{\mathrm{b}}$.

\section{Statistical analysis}

Data was analyzed using STATA intercooled version 9.2. Quantitative data was analyzed using ANOVA and post hoc Bonferroni test for comparison of the means of the five groups. When the data was not normally distributed Kruskal - Wallis test and MannWhitney test was used. Correlation analysis was performed by using Pearson's correlation test. Qualitative data was compared using Chi square test. Comparisons were made between all groups individually to try to deduct which factors were significant between groups G1 compared normal vs. suspect, G2 compared normal vs. mild KC, G3 compared normal vs. moderate KC, G4 compared normal vs. severe KC, G5 compared suspect vs. mild KC, G6 compared suspect vs. moderate KC, G7 compared suspect vs. severe KC, G8 compared mild $\mathrm{KC}$ vs. moderate $\mathrm{KC}$, G9 compared mild $\mathrm{KC}$ vs. severe $\mathrm{KC}$, G10 compared moderate KC vs. severe KC. $P$ value was considered significant if it was $\leq 0.05$.

\section{Results}

Demographic features of patients in normal eyes as control group along with the suspect $\mathrm{KC}$ and the other three groups of $\mathrm{KC}$ are stated in Table 1.

Table 2 and 3 shows anterior segment characteristics and corneal aberrations respectively. All parameters showed statistically significant differences between all groups $(p<0.0001$, one way ANOVA).

As expected the thinnest corneal thickness and corneal thickness at apex were significantly different in all comparison groups. Comparing suspect $\mathrm{KC}$ parameters against the mild $\mathrm{KC}$ parameters most of the values did not show any significance except for the anterior corneal power reading values $(p=0.001)$.

Corneal volume was proved to be significant in comparing normal vs suspect $\mathrm{KC}$ group as well as in normal vs mild $\mathrm{KC}$ and normal vs moderate KC. Yet there was no correlation between steep keratometry and CV. ACD values showed inconsistent differences between groups. Posterior corneal elevation showed differences between all groups (Table 4).

Total RMS, RMS coma and BCV f and BCV b were significant for most groups except for the group 5 (Table 5).

Correlation of steep anterior keratometry showed significance with all parameters except corneal volume. Steep K revealed negative correlation with thinnest corneal point and thickness at apex which to be expected (Table 6).

There was strong positive correlation between anterior steep keratometry and all corneal aberrations $(\mathrm{p}=0.0001)$. The BCV parameter showed a positive correlation as well (Figure 1).

\begin{tabular}{|l|l|l|l|l|l|}
\hline \multicolumn{7}{|l|}{ Table 1: Demographic features of patients. } \\
\hline Feature & $\begin{array}{l}\text { Normal } \\
\mathbf{N = 5 0}\end{array}$ & $\begin{array}{l}\text { Suspect } \\
\mathbf{N = 8 2}\end{array}$ & $\begin{array}{l}\text { Mild KC } \\
\mathbf{N = 8 0}\end{array}$ & $\begin{array}{l}\text { Moderate KC } \\
\mathbf{N = 1 4 2}\end{array}$ & $\begin{array}{l}\text { Severe KC } \\
\mathbf{N = 9 6}\end{array}$ \\
\hline $\begin{array}{l}\text { Age } \\
\text { Mean } \pm \text { SD } \\
\text { (range) }\end{array}$ & $\begin{array}{l}26.7 \pm 6.0 \\
(17-44)\end{array}$ & $\begin{array}{l}27.4 \pm 9.3 \\
(13-59)\end{array}$ & $\begin{array}{l}28.9 \pm 10.7 \\
(12-66)\end{array}$ & $\begin{array}{l}26.2 \pm 9.5 \\
(10-52)\end{array}$ & $\begin{array}{l}23.6 \pm 7.7 \\
(10-52)\end{array}$ \\
\hline Sex Male\% & $46 \%$ & $52.4 \%$ & $57.5 \%$ & $48.6 \%$ & $39.6 \%$ \\
\hline Eye Rt/ Lt & $29 / 21$ & $42 / 40$ & $45 / 35$ & $70 / 72$ & $44 / 52$ \\
\hline
\end{tabular}


Table 2: Anterior segment parameters and their comparisons between groups

\begin{tabular}{|c|c|c|c|c|c|}
\hline $\begin{array}{l}\text { Parameters } \\
\text { Mean } \pm \text { SD }\end{array}$ & Normal $\mathrm{N}=50$ & $\begin{array}{l}\text { Suspect } \\
\mathrm{N}=82\end{array}$ & $\begin{array}{l}\text { Mild KC } \\
\mathrm{N}=80\end{array}$ & $\begin{array}{l}\text { Moderate KC } \\
\mathrm{N}=142\end{array}$ & $\begin{array}{l}\text { Severe KC } \\
N=96\end{array}$ \\
\hline Thinnest location (um) & $526.7 \pm 38.9$ & $484.3 \pm 41.2$ & $473.1 \pm 40.4$ & $442.5 \pm 49.2$ & $384.2 \pm 56.2$ \\
\hline CT at apex (um) & $579.1 \pm 63.0$ & $529.4 \pm 55.2$ & $507.1 \pm 60.5$ & $472.9 \pm 52.6$ & $422.1 \pm 68.9$ \\
\hline $\mathrm{ACD}(\mathrm{mm})$ & $3.1 \pm 0.3$ & $3.2 \pm 0.4$ & $3.2 \pm 0.4$ & $3.3 \pm 0.3$ & $3.6 \pm 0.4$ \\
\hline Corneal volume (mm3) & $56.6 \pm 3.9$ & $52.3 \pm 4.0$ & $53.6 \pm 4.0$ & $53.9 \pm 4.1$ & $55.2 \pm 4.7$ \\
\hline Anterior mean $\mathrm{K}$ & $42.2 \pm 1.1$ & $42.5 \pm 1.3$ & $45.0 \pm 1.19$ & $47.2 \pm 1.9$ & $55.5 \pm 6.1$ \\
\hline Posterior mean $\mathrm{K}$ & $-5.9 \pm 0.3$ & $0.45 \pm 5.9$ & $1.1 \pm 6.2$ & $0.7 \pm 6.8$ & $0.1 \pm 8.6$ \\
\hline Anterior elevation & $4 \pm 2.2$ & $9 \pm 9.1$ & $12 \pm 9.9$ & $17 \pm 12.2$ & $32 \pm 20$ \\
\hline Posterior elevation & $9.8 \pm 3.7$ & $17.7 \pm 11.9$ & $18.9 \pm 9.5$ & $28.4 \pm 17.9$ & $54.9 \pm 28.9$ \\
\hline
\end{tabular}

CT: Corneal Thickness, ACD: Anterior Chamber Depth, K: Keratometry

Table 3: Corneal aberrations parameters and their comparisons between groups.

\begin{tabular}{|c|c|c|c|c|c|}
\hline Parameters Mean \pm SD & Normal $\mathrm{N}=50$ & Suspect $\mathrm{N}=82$ & Mild KC N=80 & Moderate $\mathrm{KC} \mathrm{N}=142$ & Severe $\mathrm{KC} \mathrm{N}=96$ \\
\hline Corneal asphericity (Q) & $0.2 \pm 0.1$ & $0.3 \pm 0.3$ & $0.5 \pm 0.4$ & $0.9 \pm 0.6$ & $1.7 \pm 0.8$ \\
\hline Total RMS & $0.4 \pm 0.2$ & $0.5 \pm 0.4$ & $0.7 \pm 0.6$ & $1.2 \pm 0.7$ & $3.4 \pm 2.5$ \\
\hline RMS Spherical aberration & $0.1 \pm 0.1$ & $0.1 \pm 0.1$ & $0.2 \pm 0$ & $0.2 \pm 0.2$ & $0.7 \pm 0.7$ \\
\hline RMS coma & $0.2 \pm 0.1$ & $0.3 \pm 0.2$ & $0.5 \pm 0.6$ & $0.9 \pm 0.7$ & $2.2 \pm 1.5$ \\
\hline RMS Astigmatism & $-0.1 \pm 0.7$ & $1.6 \pm 1.4$ & $2.3 \pm 2.6$ & $4.1 \pm 3.4$ & $6.6 \pm 5.6$ \\
\hline$B C V f$ & $0.2 \pm 0.2$ & $0.8 \pm 0.8$ & $1.1 \pm .9$ & $2.3 \pm 1.6$ & $5.4 \pm 3.0$ \\
\hline $\mathrm{BCV} b$ & $0.1 \pm 0.2$ & $0.9 \pm 0.8$ & $1.3 \pm 1.3$ & $2.5 \pm 1.7$ & $5.0 \pm 3.2$ \\
\hline
\end{tabular}

Table 4: Multiple comparisons of anterior segment parameters between groups.

\begin{tabular}{|c|c|c|c|c|c|c|c|c|c|c|}
\hline Parameters & G1 & G2 & G3 & G4 & G5 & G6 & G7 & G8 & G9 & G10 \\
\hline ACD & 0.84 & 0.34 & 0.006 & $<0.001$ & 1.00 & 0.62 & $<0.0001$ & 1.00 & $<0.0001$ & $<0.0001$ \\
\hline Thinnest location & $<0.0001$ & $<0.0001$ & $<0.0001$ & $<0.0001$ & 1.00 & $<0.0001$ & $<0.0001$ & $<0.0001$ & $<0.0001$ & $<0.0001$ \\
\hline CT at apex & $<0.0001$ & $<0.0001$ & $<0.0001$ & $<0.0001$ & 0.18 & $<0.0001$ & $<0.0001$ & $<0.0001$ & $<0.0001$ & $<0.0001$ \\
\hline Corneal volume & 0.03 & 0.001 & 0.002 & 0.71 & 1.00 & 1.00 & 1.00 & 1.00 & 0.12 & 0.19 \\
\hline Ant. mean $\mathrm{K}$ & 1.00 & $<0.0001$ & $<0.0001$ & $<0.0001$ & 0.001 & $<0.0001$ & $<0.0001$ & $<0.0001$ & $<0.0001$ & $<0.0001$ \\
\hline Post mean K & $<0.0001$ & $<0.0001$ & $<0.0001$ & $<0.0001$ & 1.00 & 1.00 & 1.00 & 1.00 & 1.00 & 1.00 \\
\hline Ant. elevation & 0.0001 & 0.0001 & 0.0001 & 0.0001 & 0.16 & 0.0001 & 0.0001 & 0.0001 & 0.0001 & 0.0001 \\
\hline Post. elevation & 0.0001 & 0.0001 & 0.0001 & 0.0001 & 0.12 & 0.0001 & 0.0001 & 0.0001 & 0.0001 & 0.0001 \\
\hline
\end{tabular}

Table 5: Multiple comparisons of corneal aberrations parameters between groups.

\begin{tabular}{|c|c|c|c|c|c|c|c|c|c|c|}
\hline Parameters & G1 & G2 & G3 & G4 & G5 & G6 & G7 & G8 & G9 & G10 \\
\hline Total RMS & 0.0007 & 0.0001 & 0.0001 & 0.0001 & 0.03 & 0.0001 & 0.0001 & 0.0001 & 0.0001 & 0.0001 \\
\hline $\mathrm{Q}$ & 1.00 & 0.02 & $<0.0001$ & $<0.0001$ & 0.29 & $<0.0001$ & $<0.0001$ & $<0.0001$ & $<0.0001$ & $<0.0001$ \\
\hline RMS SA & 0.51 & 0.48 & 0.002 & 0.0001 & 0.15 & 0.01 & 0.0001 & 0.0003 & 0.0001 & 0.0001 \\
\hline RMS coma & 0.0001 & 0.0001 & 0.0001 & 0.0001 & 0.009 & 0.0001 & 0.0001 & 0.0001 & 0.0001 & 0.0001 \\
\hline RMS Astigmatism & 0.98 & 0.001 & 0.0001 & 0.0001 & 0.0001 & 0.0001 & 0.0001 & 0.0001 & 0.0001 & 0.0001 \\
\hline$B C V f$ & 0.0001 & 0.0001 & 0.0001 & 0.0001 & 0.06 & 0.0001 & 0.0001 & 0.0001 & 0.0001 & 0.0001 \\
\hline $\mathrm{BCV} b$ & 0.0001 & 0.0001 & 0.0001 & 0.0001 & 0.20 & 0.0001 & 0.0001 & 0.0001 & 0.0001 & 0.0001 \\
\hline
\end{tabular}

Q: Corneal Asphericity, RMS: Root Mean Square, BCV f: Baiocchi Calossi Versaci front index, BCV b: Baiocchi Calossi Versaci back index.

Table 6: Correlation between steep anterior keratometry and other parameters.

\begin{tabular}{|l|l|l|}
\hline Parameters & Correlation co-efficient & P value \\
\hline ACD (mm) & 0.52 & $<0.0001^{*}$ \\
\hline Thinnest location (um) & -0.73 & $<0.0001^{*}$ \\
\hline CT at apex (um) & -0.59 & $<0.0001^{*}$ \\
\hline Corneal volume (mm2) & 0.07 & 0.12 \\
\hline Anterior flat K & 0.94 & $<0.0001^{*}$ \\
\hline Posterior flat K & 0.04 & 0.38 \\
\hline Posterior steep K & 0.02 & 0.69 \\
\hline Ant. elevation & 0.33 & $0.05^{\star}$ \\
\hline Post. elevation & 0.71 & $<0.0001^{*}$
\end{tabular}




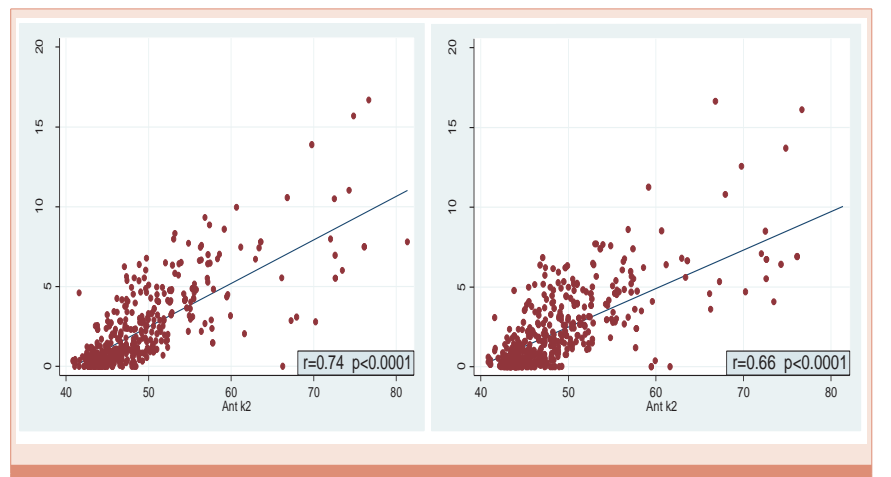

Figure 1: Correlation between anterior steep kertometry \& $B C V_{f}$ and $B C V_{b}$.

\section{Discussion}

Detection of keratoconus is particularly important among patients considering refractive surgery in whom the presence of keratoconus and keratoconus suspect would yield unsatisfactory results and cause postoperative complications as corneal ectasia. ${ }^{28}$ Difficulty recognizing keratoconus arises with very early or preclinical stages of the ectatic disorder [24,29-31].

The Scheimpflug placido imaging technology (Sirius) is a relatively new advancement that has been reported to be highly reproducible and repeatable $[27,32,33]$. To the best of our knowledge, this is the first study that investigated the characterization of anterior segment parameters of keratoconus eyes using the Scheimpflug-placido Sirius topographer in a Southern Egyptian population.

This study showed that several indices derived from Sirius measurements, including pachymetric readings and anterior and posterior corneal power along with corneal posterior elevation are helpful in discriminating eyes with different degrees of keratoconus from normal eyes. The TCT and posterior elevation seemed to be the best in discriminating suspect keratoconus eyes from normal eyes.

As corneal thinning is a key pathological feature of keratoconus; decrease of CCT and TCT is a distinguished sign of progression in the current study and can be used in monitoring the progression of the disease [20].

Schlegel et al. [12], used the Orbscan IIz slit-scanning topography on 60 normal myopic patients and 48 keratoconus suspect patients. They found that the differences between the keratoconus suspect group and normal group were statistically significant for thinnest pachymetries. In contrast, Rao et al. [34], did not find statistically significant differences in the mean central and thinnest point pachymetry values between keratoconus suspect patients and a control group. While Nilforoushan et al. [13], found that the suspect group had thinner pachymetry using the Pentacam.

In our study we found that the differences between the keratoconus group, suspect group and normal group were statistically significant in corneal thickness at apex and at thinnest location.

In the current study, the value of central ACD in normal group is slightly lower than those of Edmonds et al. [35], that used Scheimpflug photography $(3.13 \pm 0.3$ versus $3.18 \pm 0.32 \mathrm{~mm})$. Our results showed progressively longer ACD values at center in mild, moderate and severe keratoconus subjects, with the highest values in the last group as in Abolbashari et al. study [36].

Corneal volume was recently investigated as an additive screening factor for keratoconus. In the present study the corneal volume measurements in eyes with mild to moderate keratoconus were significantly lower than those in a group of normal eyes which was similar to most reported studies $[21,22,37,38]$. In contrast Pinero et al. [22], reported inconsistent findings and that grade I KC did not show decrease in CV when compared to grade II KC. Yet in our study there was weak positive correlation between $\mathrm{K}$ and $\mathrm{CV}(0.07)$.

Gordon-Shaag et al. [39], reported that corneal higher order aberrations were found to be significantly higher for keratoconic than normal eyes, but for suspect keratoconus the results were mixed. Alio et al. [24], has established corneal aberrometry as a potential diagnostic tool for diagnosing keratoconus especially coma-like aberrations.

On the basis of previous studies showing that higher-order aberrations of the anterior corneal surface can be used as a tool to detect and grade keratoconus, we measured the front and back corneal surface root mean square of higher-order aberrations [24].

In our study corneal higher order aberrations were found to be higher for keratoconic than normal eyes as in Coma like aberration normal was $0.2 \pm 0.1 \mathrm{um}$, suspect was $0.3 \pm 0.2 \mathrm{um}$, mild was $0.5 \pm 0.6$ um,moderate was $0.9 \pm 0.7 \mathrm{um}$ and severe was $2.2 \pm 1.5 \mathrm{um}$ but in spherical aberrations there was no difference between normal and suspect $\mathrm{KC}$, mild and moderate $\mathrm{KC}$ but significantly higher in severe group of KC. Our study found also progressive increase in $\mathrm{BCV}_{\mathrm{f}} \mathrm{BCV}$ ${ }_{b}$ values (which are a combination of corneal high order aberrations) in suspect keratoconus and keratoconus subjects than normal corneas.

Several studies have addressed the topic of posterior corneal elevation and its relevance to early detection 1 keratoconus and that it is a useful index for discriminating this disease $[17,34]$. In the current study we found that posterior corneal elevation measured with the Sirius is higher in eyes with keratoconus or subclinical keratoconus than in normal corneas. As posterior elevation in normal was 9.8 \pm 3.7 , in suspect was $17.7 \pm 11.9$, in mild was $18.9 \pm 9.5$, in moderate was $28.4 \pm 17.9$ and in severe was $54.9 \pm 28.9$.

In conclusion, Sirius is a valuable tool in diagnosing KC especially KC suspect and early KC.

\section{References}

1. Pinero DP, Nieto JC, Lopez-Miguel A (2012) Characterization of corneal structure in keratoconus. J Cataract Refract Surg 38: 2167-2183.

2. Fontes BM, Ambrósio R Jr, Jardim D, Velarde GC, Nosé W (2010) Corneal biomechanical metrics and anterior segment parameters in mild keratoconus. Ophthalmology 117: 673-679.

3. Rabinowitz YS (1998) Keratoconus. Surv Ophthalmol 42: 297-319.

4. Wilson SE, Lin DT, Klyce SD (1991) Corneal topography of keratoconus. Cornea 10: 2-8.

5. Maeda N, Klyce SD, Smolek MK, Thompson HW (1994) Automated keratoconus screening with corneal topography analysis. Invest Ophthalmol Vis Sci 35: 2749-2757. 
6. Rabinowitz YS (1995) Videokeratographic indices to aid in screening for keratoconus. J Refract Surg 11: 371-379.

7. Smolek MK, Klyce SD (1997) Current keratoconus detection methods compared with a neural network approach. Invest Ophthalmol Vis Sci 38: 2290-2299.

8. Rabinowitz YS, Rasheed K (1999) KISA\% index: a quantitative videokeratography algorithm embodying minimal topographic criteria for diagnosing keratoconus. J Cataract Refract Surg 25: 1327-1335.

9. Auffarth GU, Wang L, Volcker HE (2000) Keratoconus evaluation using the Orbscan Topography System. J Cataract Refract Surg 26: 222-228.

10. Pflugfelder SC, Liu Z, Feuer W, Verm A (2002) Corneal thickness indices discriminate between keratoconus and contact lens-induced corneal thinning Ophthalmology 109: 2336-2341.

11. Fam HB, Lim KL (2006) Corneal elevation indices in normal and keratoconic eyes. J Cataract Refract Surg 32: 1281-1287.

12. Schlegel Z, Hoang-Xuan T, Gatinel D (2008) Comparison of and correlation between anterior and posterior corneal elevation maps in normal eyes and keratoconus-suspect eyes. J Cataract Refract Surg 34: 789-795.

13. Nilforoushan MR, Speaker M, Marmor M, Abramson J, Tullo W, et al. (2008) Comparative evaluation of refractive surgery candidates with Placido topography, Orbscan II, Pentacam, and wavefront analysis. J Cataract Refract Surg 34: 623-631.

14. Maeda N, Klyce SD, Smolek MK (1995) Neural network classification of corneal topography. Preliminary demonstration. Invest Ophthalmol Vis Sci 36: $1327-1335$

15. Schwiegerling J, Greivenkamp JE (1996) Keratoconus detection based on videokeratoscopic height data. Optom Vis Sci 73: 721-728.

16. Langenbucher A, Gusek-Schneider GC, Kus MM, Huber D, Seitz B (1999) [Keratoconus screening with wave-front parameters based on topography height data]. Klin Monbl Augenheilkd 214: 217-223.

17. de Sanctis U, Loiacono C, Richiardi L, Turco D, Mutani B, et al. (2008) Sensitivity and specificity of posterior corneal elevation measured by Pentacam in discriminating keratoconus/subclinical keratoconus. Ophthalmology 115: 1534-1539.

18. Tomidokoro A1, Oshika T, Amano S, Higaki S, Maeda N, et al. (2000) Changes in anterior and posterior corneal curvatures in keratoconus. Ophthalmology 107: 1328-1332.

19. Bessho K, Maeda N, Kuroda T, Fujikado T, Tano Y, et al. (2006) Automated keratoconus detection using height data of anterior and posterior cornea surfaces. Jpn J Ophthalmol 50: 409-416.

20. Ucakhan OO, Cetinkor V, Ozkan M, Kanpolat A (2011) Evaluation of Scheimpflug imaging parameters in subclinical keratoconus, keratoconus, and normal eyes. J Cataract Refract Surg 37: 1116-1124.

21. Ambrosio R, Jr., Alonso RS, Luz A, Coca Velarde LG (2006) Cornealthickness spatial profile and corneal-volume distribution: tomographic indices to detect keratoconus. J Cataract Refract Surg 32: 1851-1859.

22. Piñero DP, Alió JL, Alesón A, Escaf Vergara M, Miranda M (2010) Corneal volume, pachymetry, and correlation of anterior and posterior corneal shape in subclinical and different stages of clinical keratoconus. J Cataract Refract Surg 36: 814-825.
23. Milla M, Pinero DP, Amparo F, Alio JL (2011) Pachymetric measurements with a new Scheimpflug photography-based system: intraobserver repeatability and agreement with optical coherence tomography pachymetry. J Cataract Refract Surg 37: 310-316.

24. Alio JL, Shabayek MH (2006) Corneal higher order aberrations: a method to grade keratoconus. J Refract Surg 22: 539-545.

25. Jafri B, Li X, Yang H, Rabinowitz YS (2007) Higher order wavefront aberrations and topography in early and suspected keratoconus. J Refract Surg 23: 774-781.

26. Lim L, Wei RH, Chan WK, Tan DT (2007) Evaluation of higher order ocular aberrations in patients with keratoconus. J Refract Surg 23: 825-828.

27. Masoud M, Livny E, Bahar I (2015) Repeatability and intrasession reproducibility obtained by the Sirius anterior segment analysis system. Eye Contact Lens 41: 107-110.

28. Randleman JB, Russell B, Ward MA, Thompson KP, Stulting RD (2003) Risk factors and prognosis for corneal ectasia after LASIK. Ophthalmology 110 : 267-275.

29. Piñero DP, Alió JL, Alesón A, Escaf M, Miranda M (2009) Pentacam posterior and anterior corneal aberrations in normal and keratoconic eyes. Clin Exp Optom 92: 297-303.

30. Gobbe M, Guillon M (2005) Corneal wavefront aberration measurements to detect keratoconus patients. Cont Lens Anterior Eye 28: 57-66.

31. Accardo PA, Pensiero S (2002) Neural network-based system for early keratoconus detection from corneal topography. J Biomed Inform 35: 151159.

32. Nasser CK, Singer R, Barkana Y, Zadok D, Avni I, et al. (2012) Repeatability of the Sirius imaging system and agreement with the Pentacam HR. J Refract Surg 28: 493-497.

33. De la Parra-Colin P, Garza-Leon M, Barrientos-Gutierrez T (2014) Repeatability and comparability of anterior segment biometry obtained by the Sirius and the Pentacam analyzers. Int Ophthalmol 34: 27-33.

34. Rao SN, Raviv T, Majmudar PA, Epstein RJ (2002) Role of Orbscan II in screening keratoconus suspects before refractive corneal surgery. Ophthalmology 109: 1642-1646.

35. Edmonds CR, Wung SF, Pemberton B, Surrett S (2009) Comparison of anterior chamber depth of normal and keratoconus eyes using Scheimpflug photography. Eye Contact Lens 35: 120-122.

36. Abolbashari F, Mohidin N, Ahmadi Hosseini SM, Mohd Ali B, Retnasabapathy S (2013) Anterior segment characteristics of keratoconus eyes in a sample of Asian population. Cont Lens Anterior Eye 36: 191-195.

37. Mannion LS, Tromans C, O'Donnell C (2011) Reduction in corneal volume with severity of keratoconus. Curr Eye Res 36: 522-527.

38. Emre S, Doganay S, Yologlu S (2007) Evaluation of anterior segment parameters in keratoconic eyes measured with the Pentacam system. J Cataract Refract Surg 33: 1708-1712.

39. Gordon-Shaag A, Millodot M, Ifrah R, Shneor E (2012) Aberrations and topography in normal, keratoconus-suspect, and keratoconic eyes. Optom Vis Sci 89: 411-418. 